\title{
Arquitetar para ensinar: design instrucional no ensino remoto
}

\author{
Think up to teach well: instructional design for remote learning \\ Anamaria Siriani de Oliveira ${ }^{1}$ (D), Lúcia de Rezende Jayme² (D), Fausto Almeida ${ }^{3}$ (D), Fábio Carmona ${ }^{4}$ (D)
}

\begin{abstract}
RESUMO:
A pandemia causada pelo novo coronavírus (SARS-CoV-2) impôs um cenário mundial de isolamento social e suspensão de atividades didáticas presenciais em todos os níveis de ensino. Isto levou à adoção emergencial de estratégias de ensino remoto para dar continuidade, ainda que de forma limitada, às atividades didáticas. Por outro lado, boa parte dos professores, em todos os níveis de ensino, possuía pouco ou nenhum conhecimento e experiência com o ensino remoto. Embora as instituições de ensino tenham oferecido suporte, em maior ou menor grau, coube individualmente ao docente a maior parte da tarefa de se capacitar, preparar e oferecer suas unidades de ensino. Além disso, muitos cursos foram transferidos para o ambiente virtual sem as devidas adaptações, o que pode resultar em piores resultados de aprendizagem. Embora existam diferentes metodologias para planejar e implantar o ensino à distância, usando plataformas baseadas na rede mundial de computadores, o modelo ADDIE é bastante popular e relativamente simples de ser implantado e, por isso, foi escolhido para o desenvolvimento deste artigo. Dessa forma, apresentamos as etapas de análise, desenho, desenvolvimento, implementação e avaliação de curso oferecido de forma online. Além disso, incluímos elementos práticos como indicação de equipamentos, softwares, links e sugestões para completar estas etapas.
\end{abstract}

Palavras-chave: Educação à Distância; Aprendizagem Online; Planejamento, Inclusão Educacional, Avaliação Educacional, COVID-19

\begin{abstract}
:
The pandemic caused by the new coronavirus (SARS-CoV-2) imposed a worldwide scenario of social isolation and suspension of face-to-face teaching activities at all levels of education. It has forced the emergency adoption of remote teaching strategies to maintain the continuity of the didactic activities, even though in a limited way. On the other hand, most teachers, at all levels of education, had barely or no knowledge and experience with remote teaching. Although the educational institutions offered support, to some degree or another, it was up to individual teachers to do most of theirselves training, prepare, and deliver their subjects. Also, many courses were migrated to the virtual learning environment without the proper adaptations, which may result in worse learning outcomes. Although there are different methodologies for planning and implementing e-learning, the ADDIE model is largely popular and relatively simple to implement, and for this reason, it was chosen for the development of this article. Thus, we present the steps of analysis, design, development, implementation, and evaluation of a remote course. Additionally, we include practical elements such as an indication of equipment, software, links, and suggestions to accomplish these steps.
\end{abstract}

Keywords: e-learning; online learning; planning; educational inclusion, assessment, COVID-19

1. Universidade de São Paulo. Faculdade de Medicina de Ribeirão Preto, Ribeirão Preto, SP, Brasil. Professora Associada do Departamento de Ciências da Saúde.

2. Universidade de São Paulo. Faculdade de Medicina de Ribeirão Preto, Ribeirão Preto, SP, Brasil. Escritório de Relações Internacionais e Centro de Desenvolvimento Docente.

3. Universidade de São Paulo. Faculdade de Medicina de Ribeirão Preto, Ribeirão Preto, SP, Brasil. Professor Doutor do Departamento de Bioquímica e Imunologia.

${ }^{4}$. Universidade de São Paulo. Faculdade de Medicina de Ribeirão Preto, Ribeirão Preto, SP, Brasil. Professor Associado do Departamento de Puericultura e Pediatria. 


\section{MENSAGENS PRINCIPAIS:}

- A implantação de um curso ou disciplina em formato online, parcial ou totalmente, requer cuidadoso planejamento e a escolha de um modelo de design instrucional auxilia na sistematização.

- Planejar e implantar uma unidade de ensino online é uma ótima oportunidade para revisar seus métodos educacionais, incluir maior interação entre e com os estudantes e o compartilhamento de experiências, abandonando o ultrapassado modelo centrado exclusivamente no professor (Sage on the stage).

- Unidades de ensino estão em constante desenvolvimento e melhoria, e os estudantes são uma ótima fonte de informações sobre o que pode ser aprimorado.

\section{CONTEXTO}

O termo design instrucional pode parecer uma novidade, no entanto, os leitores irão notar que nada mais é que a sistematização das etapas que vão do planejamento dos objetivos de ensino-aprendizagem até a avaliação da efetividade e aceitação do ambiente virtual de ensino por parte dos estudantes. Embora o termo esteja diretamente vinculado ao ensino remoto (ER) ou educação à distância $(E a D)$, essas etapas poderiam ser utilizadas também, com pequena adaptação, para o planejamento de aulas presenciais.

No entanto, as semelhanças encerram-se nas etapas sistemáticas, porque a dinâmica e recursos de ensino são bastante distintos quando pensamos em modelos de ensino presencial e a distância. O ideal é não adotar as mesmas formas de ensinar do presencial quando o conteúdo está sendo oferecido, ainda que parcialmente, em plataformas de EaD. Em especial, a duração das aulas, a necessidade de planejar intencionalmente oportunidades de interação do professor com os estudantes e entre eles e a possibilidade de incorporar tecnologias de comunicação e informação, tornam o ensino remoto distinto do presencial.
Em muitos aspectos essas diferenças entre ensino presencial e remoto podem ser tanto positivas quanto negativas para estudantes e professores. Apenas como um exemplo, ao mesmo passo que a adoção do ensino remoto possibilita que o conteúdo chegue a um número grande de estudantes, como nos cursos do tipo MOOC (da Língua Inglesa: Massive Open Online Course), por outro lado a adoção maciça de tecnologia e estratégias ativas de ensino-aprendizagem pode resultar em pior aproveitamento dos estudantes, sem mencionar os desafios para desenvolver design instrucionais que possibilitem o desenvolvimento de habilidade procedimentais e atitudinais típicas de profissionais de saúde.

O cenário atual, imposto pela pandemia da Covid-19, levou boa parte do mundo a adotar o ensino remoto como forma de minimizar os efeitos do distanciamento social nas escolas e universidades. Com os olhos já em um futuro, que esperamos estar próximo, as adaptações inicialmente feitas de forma emergencial em nossas disciplinas, unidades de ensino ou cursos como um todo podem ser revistas e melhoradas e, ainda, poderão ser aproveitadas como parte de formas híbridas de ensino. Dessa forma, os objetivos deste artigo são:

1. Discutir a importância do design instrucional para o planejamento e implementação de cursos ou disciplinas utilizando estratégias de ER e EaD;

2. Apresentar o modelo ADDIE para design instrucional;

3. Discutir cada etapa do planejamento, apresentando sugestões para o contexto do ensino de graduação e pós-graduação nas profissões da saúde.

\section{A IMPORTÂNCIA DO DESIGN INSTRU- CIONAL}

A relevância do design instrucional, no contexto do ensino superior, é facilmente percebida se pensarmos em princípios básicos da educação de adultos e teorias primárias de aprendizagem. Nesta lógica, destacamos a teoria da carga cognitiva como tese que influencia a forma que o design instrucional pode oportunizar diferentes estilos e experiências de aprendizagem ${ }^{1}$. 
A teoria da carga cognitiva é interessante para fundamentar a ER/EaD, já que esta modalidade de ensino requer maior assertividade por parte do docente na definição de objetivos do curso, escolha de materiais didáticos e bibliografia requerida, bem como a elaboração de atividades e avaliações do estudante. Nesse modelo cognitivista, o estudante tem um papel ativo no aprendizado e o instrutor provê estratégias que permitem ao estudante fazer conexões entre 0 conhecimento que traz consigo e o novo que deverá aprender.

Em linhas bastante gerais, o princípio desta teoria é que, considerando que o cérebro humano consegue reter um limitado número de informações na memória de curta duração, um ambiente de aprendizagem eficiente é aquele que fomenta a capacidade do processo de cognição e memória. Para tal, é preciso reduzir a carga de informação irrelevante (utilização de materiais redundantes, ex: texto descritivo para explicar um gráfico facilmente inteligível pelos sinais de positivo/negativo), incrementar a carga intrínseca (dado pela complexidade do material didático, ex: apresentar diferentes esquemas e fazer com que o estudante os relacione) e, assim, promover a carga relevante natural (decorrente das atividades de ensino que possibilitam a aprendizagem $)^{1,2}$.

Existem diferentes modelos ou abordagens para o desenvolvimento de cursos ou disciplinas. Em uma lista que não pretende ser completa, podemos citar os principais: o modelo ADDIE (analyze, design, develop, implement, evaluate), - modelo OCL (online collaborative learning), a aprendizagem baseada em competências, as comunidades de prática e o design ágil. Neste artigo, detalharemos os elementos do modelo ADDIE $^{3}$ porque este se assemelha mais a experiência, ainda que não sistematizada, da maioria dos professores que, devido à pandemia da Covid-19, estão dando seus primeiros passos na transição para o ER/EaD. Assim como outras variedades de design instrucional que recomendam as fases de análise, desenho, desenvolvimento, implementação e avaliação, o ADDIE fornece uma estrutura de orientação para o desenvolvi- mento de uma educação consistente e efetiva ${ }^{1}$. Entretanto, sugerimos que se conheça e explore os demais modelos, ampliando assim os recursos à sua disposição, ou seja, "recheando" sua caixa de ferramentas docente.

\section{O MODELO ADDIE}

O modelo ADDIE foi desenvolvido a partir de experiências de treinamento militar norte americano na modalidade de EaD. O modelo ADDIE tem sido considerado relativamente simples, devido à sua efetiva aplicação a necessidades de ensino amplas e complexas, quando comparado a modelos como o de Dick e Carey e o $4 \mathrm{CD} / \mathrm{ID}^{4}$.

As principais vantagens de se empregar um modelo como o ADDIE são a maior qualidade geral do curso, objetivos de aprendizagem claros, conteúdos estruturados, delimitação de carga horária, maior disponibilidade de acesso a conteúdos, maior conexão entre a avaliação e os objetivos de aprendizagem, considerando avaliações formativas e somativas. Este modelo também possui limitações. Entre elas, destacamos que cursos mais simples e com número pequeno de participantes podem tornar-se desnecessariamente complexos e caros. Outra limitação é que o modelo ADDIE é mais centrado no desenvolvimento de conteúdo, não dando a mesma ênfase na comunicação e interação entre estudantes e professores, o que pode ser parcialmente remediado com a escolha apropriada de recursos como fóruns e chats dentro do ambiente virtual de aprendizagem. Por fim, o modelo ADDIE apresenta apenas linhas gerais de planejamento, não incluindo instruções claras para tomada de decisão a respeito de quais tecnologias e métodos empregar. Cabe ao professor a decisão, baseando-a em sua experiência pessoal e no contexto em que se insere o curso (estudantes, competências, área do conhecimento, recursos tecnológicos disponíveis etc.).

O modelo ADDIE é composto por cinco elementos que ocorrem em loop, ou seja, o último elemento (avaliação) leva de volta ao primeiro (análise) como pode ser visto na Figura 1. 


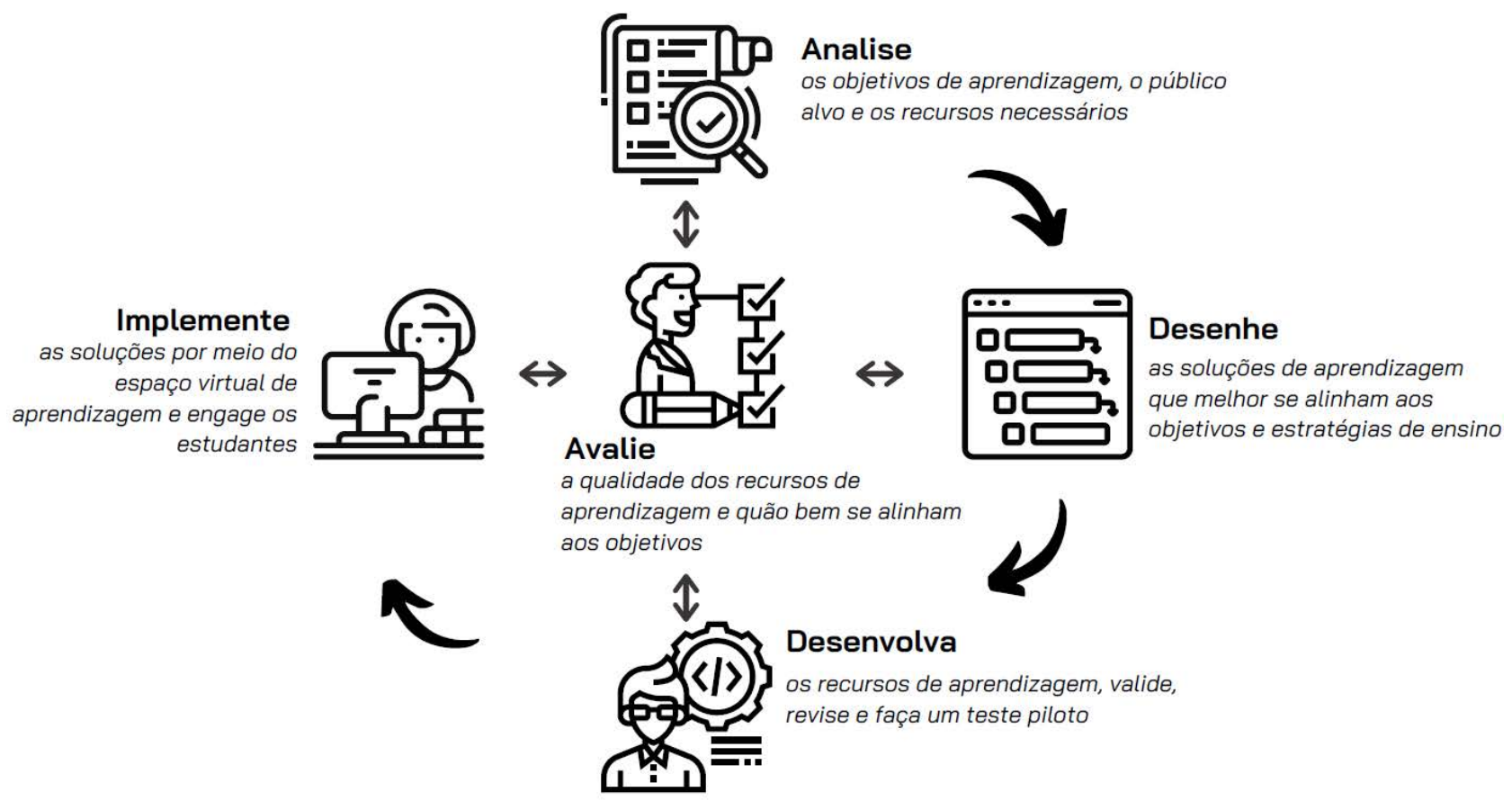

Figura 1: Representação das etapas do modelo ADDIE (analyze, design, develop, implement, evaluate) com suas respectivas definições. Nota-se que nesse esquema a avaliação foi colocada como central no processo e acontecendo durante todas as fases de elaboração e implantação da unidade de ensino remoto. Fonte: os próprios autores.

O modelo ADDIE fornece uma abordagem sistemática para o planejamento e implantação de uma experiência de aprendizagem rica e eficaz. A implementação, abordagens e instruções de cada fase serão discutidas ao longo do artigo. Nas diferentes fases, o estudante, o contexto e os materiais instrucionais são analisados e abordados a fim de estabelecer um eficiente contexto de aprendizagem. Portanto, o design instrucional permite a identificação das características do público-alvo, para o qual deve ser considerado o conhecimento existente e experiências prévias, os interesses e atitudes, e assim, determinar os objetivos e ambiente/contexto de aprendizagem. $O$ conteúdo instrucional e os instrumentos de avaliação (formativo e somativo) são implementados de forma a apoiar os estudantes e seus objetivos de aprendizagem.

\section{Analisar (Analyze)}

Esta primeira etapa consiste em investigar o contexto educacional em que determinada uni- dade de ensino será implementada, perpassando prioritariamente questões técnicas como, por exemplo, velocidade mínima da conexão à Internet a que os estudantes terão acesso e familiaridade destes com ferramentas tecnológicas. Esta etapa também pode caracterizar o público-alvo ao qual o curso será destinado, incluindo desde características primárias, como faixa etária, até particularidades mais sutis, como expectativa em relação ao conteúdo que será ofertado ou motivação do estudante ao participar do curso ou disciplina.

Há que se decidir pelo tipo de design instrucional. Um design instrucional aberto requer um ambiente virtual de aprendizagem que permita simular a experiência presencial de ensino e é indicado para os primeiros contatos no ensino remoto, p. ex, para estudantes de graduação. Por outro lado, o design instrucional contextualizado é mais apropriado para participantes que já compartilham de conhecimento teórico-prático mais consolidado e estão aptos a inovar ou discutir boas práticas, como é comum aos estudantes de pós-graduação stricto sensu e residentes. 
Neste sentido, podemos destacar as seguintes ações que ajudarão a compreender o perfil do aluno que servirá de referência para o planejamento do curso ${ }^{5}$ :

1. Determinar os objetivos gerais do curso e identificar as necessidades de aprendizagem: Por que a ação educacional precisa ser realizada? Quais são as competências que se espera que os estudantes desenvolvam? O que o estudante espera ao ter contato com determinado conhecimento e o que o motiva a aprender?

2. Identificar o público-alvo: A qual grupo social ou econômico e a que faixa etária pertencem? Quais conhecimentos prévios trarão para o curso? Em qual contexto o conteúdo poderá ser aplicado ou quais problemas poderá resolver?

3. Determinar se o ambiente de aprendizagem será aberto ou contextualizado, e quais recursos serão necessários para desenho do conteúdo. Quais profissionais, e em qual número devem estar envolvidos?

Ainda nesta etapa, há a verificação de restrições e, também, propostas de soluções para tais limitações ${ }^{6}$. A problemática aqui a ser levantada é: O acesso à internet é ilimitado? Os participantes dominam conhecimentos em informática? Como os estudantes acessarão os materiais? Existem custos envolvidos e quais as limitações de orçamento? Há barreiras culturais ou linguísticas implicadas? Há barreiras de acessibilidade ou estudantes com necessidades especiais?

As respostas para estas questões podem ser obtidas por meio de instrumentos de pesqui$\mathrm{sa}$, tais como questionários aplicados anteriormente à realização da ação educativa, análise de materiais provenientes de edições anteriores do curso como relatórios e avaliações, ou ainda discussões preliminares com a coordenação do curso e equipe de serviços de apoio a estudantes.
Conhecer o público-alvo da unidade de ensino é, mais que um passo a ser seguido no modelo ADDIE, um fator primordial na educação de adultos, visto que a aprendizagem é centrada no estudante ao considerar: o indivíduo menos dependente, mais autodirigido e possuidor de experiências que se transformam em recursos para a aquisição do conhecimento; que o ímpeto de aprender é intrínseco ao papel que o sujeito desempenha na sociedade; e que os saberes a serem aprendidos estão articulados à imediata aplicação?.

\section{Delinear (Design)}

Neste estágio, o professor já deve, em um caráter bem amplo, ter identificado os objetivos educacionais e como pretende que seus estudantes atinjam estes objetivos. Vamos assumir que o curso ou disciplina será ministrado, pelo menos em parte, online ou seja, em uma plataforma de ensino a distância. O próximo passo é detalhar, dividir os objetivos educacionais em objetivos de aprendizagem mais específicos, focados, para seu curso. Um bom ponto de partida para esta etapa é o plano de ensino e aprendizagem (PEA). A partir dos elementos do PEA, o professor poderá decidir a respeito do modelo que será adotado para seu curso, quais estratégias são as mais adequadas para cada objetivo de aprendizagem [videoaula, leitura, resolução de problemas, discussão em grupo, aprendizagem baseada em competências (mais adequado para habilidades), interação social ou informal, entre outros]. É desejável incorporar estas decisões ao PEA, criando, assim, um roteiro estruturado (storyboard) do curso, detalhando objetivos, conteúdos, estratégias, tecnologias, e modo de avaliação, em uma sequência construtiva e lógica (para exemplo consulte o Quadro 1). Ressaltamos que, ao usar este modelo, haverá maior alinhamento entre estes elementos, resultando em maior qualidade geral do curso. 
Quadro 1. Exemplo de descrição de atividade didática em um plano de ensino e aprendizagem (PEA). Nota: a cada coluna deve-se acrescentar a data e hora do oferecimento da(s) atividade(s) e o responsável pelo conteúdo.

\begin{tabular}{|c|c|c|}
\hline Tema da Atividade & $\begin{array}{l}\text { Objetivos de Aprendizagem/Re- } \\
\text { sultados esperados }\end{array}$ & $\begin{array}{l}\text { Estratégias de Ensino e Aprendi- } \\
\text { zagem/ Avaliação }\end{array}$ \\
\hline $\begin{array}{l}\text { Conceito sobre dor } \\
\text { Epidemiologia geral da dor }\end{array}$ & $\begin{array}{l}\text { Reconhecer a taxonomia, definições, } \\
\text { teorias atuais e conceitos relativos à } \\
\text { dor e a analgesia, incluindo os efeitos } \\
\text { placebo e o Nocebo } \\
\text { Avaliar o impacto da dor sobre a } \\
\text { população em geral através de sua } \\
\text { epidemiologia, e determinantes/con- } \\
\text { dicionantes }\end{array}$ & $\begin{array}{l}3 \text { Videoaulas assíncronas de } 20 \text { mi- } \\
\text { nutos } \\
\text { Avaliação Formativa } \\
\text { Pré-teste de verificação de conheci- } \\
\text { mentos prévios, com feedback adiado } \\
\text { Pós-testes com feedback imediato }\end{array}$ \\
\hline $\begin{array}{l}\text { Abordagem cognitivo compor- } \\
\text { tamental no tratamento da dor } \\
\text { crônica para o acompanhamento e } \\
\text { motivação de pacientes com dor }\end{array}$ & $\begin{array}{l}\text { Apresentar os elementos práticos das } \\
\text { técnicas: } \\
\text { - entrevista motivacional, } \\
\text { - estabelecimento de mini metas } \\
\text { - organização da agenda do paciente } \\
\text { - a criação de rede de suporte social }\end{array}$ & $\begin{array}{l}\text { Aula síncrona com } 50 \text { min, com } \\
\text { brainstorms e pausas para dúvidas, } \\
\text { no webconference, ministrada pelo } \\
\text { psicólogo convidado } \\
\text { Conteúdo avaliado na avaliação so- } \\
\text { mativa parcial da disciplina }\end{array}$ \\
\hline $\begin{array}{l}\text { Abordagem interdisciplinar da dor: } \\
\text { as clínicas de dor e interdisciplina- } \\
\text { ridade }\end{array}$ & $\begin{array}{l}\text { Valorizar o papel do trabalho em equi- } \\
\text { pe multiprofissional } \\
\text { Desenvolver habilidades de reflexão e } \\
\text { síntese escritas }\end{array}$ & $\begin{array}{l}10 \text { Videoaulas assíncrona de até } 5 \\
\text { minutos com gravações de diferentes } \\
\text { profissionais contando seu papel em } \\
\text { ambulatórios de dor multiprofissionais } \\
\text { do HCFMRP. } \\
\text { Fórum de discussão com um caso } \\
\text { clínico de dor crônica em associa- } \\
\text { ção com vários fatores psicossociais } \\
\text { relevantes e a pergunta disparadora. } \\
\text { Por que o cuidado da dor deveria ser } \\
\text { interdisciplinar? } \\
\text { Avaliação Formativa com rubrica de } \\
\text { participação no fórum }\end{array}$ \\
\hline
\end{tabular}

Existem, no mercado nacional e internacional, diferentes soluções de ambiente virtual de aprendizagem (AVA, ou, no inglês, learning management system, LMS). Entre os mais utilizados, podemos citar: Blackboard (https://www. blackboard.com/pt-br), Desire2Learn (https:// www.d2l.com/pt-br/), Canvas (https://www.instructure.com/canvas) e Moodle (https://moodle. org). O Moodle é o AVA adotado pela Universidade de São Paulo tanto para os cursos de graduação e pós-graduação (https://edisciplinas.usp.br/) quanto para os cursos de extensão (https://cursosextensao.usp.br/).

Nestes ambientes, é possível replicar o modelo tradicional de sala de aula: há unidades ou módulos, o professor seleciona material didático e discute em tempo real com os estudantes, os estudantes realizam atividades complementares, e concluem o curso ao mesmo tempo. Este tipo de abordagem pode ser chamado de síncrona, ou seja, todos os estudantes seguem o mesmo passo.
Um dos maiores desafios enfrentados ao se migrar um curso presencial para o ambiente digital é a adaptação dos instrutores. Para tanto, o professor precisa familiarizar-se com o ambiente virtual de aprendizagem que pretende utilizar, principalmente quanto aos recursos de oferta de material didático (texto, áudio, vídeo, endereços web, fóruns, conteúdo multimídia e interativo), de interação [fóruns, quizzes (ou questionários formativos), chat (bate papo), tarefas, games (jogos), bases de dados colaborativas, diários, enquetes, glossários, atividades em grupos menores e de avaliação (acompanhamento de conclusão, frequência, questionários, tarefas, fóruns, avaliações por pares). É importante que a escoIha por cada um destes recursos seja baseada na real utilidade e adequação de uma ferramenta ao objetivo de aprendizagem pretendido, e não apenas por "ser legal e moderno". Um bom começo para se familiarizar com as ferramentas do Moodle é acessar a documentação oficial (https://docs. 
moodle.org/). Recomendamos também acessar o material didático desenvolvido pelo Centro de Desenvolvimento Docente para o Ensino (CDDE) da FMRP-USP (https://cursosextensao.usp.br/course/view.php?id=1787).

Outro ponto importante a ser considerado é o uso de repositórios de conteúdo. Podemos encontrar, na Internet, todo tipo de conteúdo, sobre qualquer assunto, e de qualquer qualidade. Uma curadoria cuidadosa pode identificar material didático que pode ser utilizado em seu curso, economizando tempo e recursos na etapa do desenvolvimento.

\section{Desenvolver (Develop)}

Esta etapa do processo só deve ser iniciada, idealmente, depois que o delineamento estiver concluído. Isto é importante para que se garanta uma uniformidade visual, linguística e metodológica em todo o material didático e nas atividades.

Nesta etapa, serão selecionados os materiais didáticos já existentes ou que serão produzidos, podendo incluir, como mencionado anteriormente, textos, imagens, som e vídeo. É necessário certificar-se de ter direitos de acesso a quaisquer materiais de outras fontes, pois estes podem estar protegidos por direitos autorais. No caso do desenvolvimento de material didático, pode-se optar pelo desenvolvimento interno (pelo próprio corpo docente), ou em serviço terceirizado. No primeiro caso, é desejável que o corpo docente tenha suporte de profissionais de informática e tecnologia da informação com experiência no ambiente virtual de aprendizagem adotado para o curso. É necessário também que haja recursos de software e hardware apropriados para a produção de conteúdo (Quadro 2).

Para a gravação de áudio e/ou vídeo, recomendamos utilizar um microfone de lapela (Iigado ao computador ou a um gravador de áudio) para melhorar a qualidade do som, o que é importante para favorecer a compreensão de pessoas com deficiência auditiva ou em ambientes com ruídos (ônibus, metrô, fila de banco). Opcionalmente, os fones de ouvido (com fio) da maioria dos telefones celulares possuem microfone embutido. Além de garantir a qualidade do áudio, é muito importante que todo o material visual (imagens, textos, slides e vídeos) seja elaborados considerando a acessibilidade de pessoas com deficiência visual. Sugerimos fortemente o uso de fontes mais limpas e legíveis (sem serifa), em tamanho adequado, e com bom contraste (por exemplo, letras pretas ou escuras em fundo branco ou bem claro).

O material didático deve ser disponibilizado preferencialmente em formatos digitais livres (open format), ou seja, que todos consigam acessar sem a necessidade de softwares proprietários. O Quadro 2 também apresenta uma lista dos principais formatos abertos que podem ser utilizados para a oferta de material instrucional.

Ressaltamos que é importante utilizar conteúdo passivo (texto, vídeo) associado a atividades ou conteúdo ativo, tais como fóruns, questionários, tarefas, jogos, de forma a fomentar a aprendizagem e a interação entre estudantes e professores. A escolha destas atividades dependerá do objetivo educacional e dos recursos disponíveis no ambiente virtual de aprendizagem. Tenha em mente que é melhor que haja maior número de atividades rápidas e com objetivos simples, do que uma única atividade complexa e extensa, que pode ser frustrante para o estudante. O mesmo princípio deve ser empregado para o conteúdo passivo: leituras curtas e focadas, vídeos curtos e objetivos, e imagens significativas. Lembre-se, menos é mais.

Ao final da etapa de desenvolvimento, é também recomendável que o processo seja validado. A melhor forma de fazer isto é convidar colegas professores e ex-alunos para testarem as funcionalidades e a coerência da plataforma. Receba e considere as sugestões deles, refine suas estratégias, explore e considere o uso de novas tecnologias.

\section{Implementar (Implement)}

Nesta terceira etapa, movimentar é a palavra-chave. Embora as tarefas que envolvem a implementação possam variar de acordo com o tipo de modelo instrucional escolhido e atividades educativas a serem aplicadas ${ }^{1,6,8}$, esse passo é caracterizado pelo agrupamento de todos os procedimentos garantindo que o que foi anteriormente 
planejado e desenvolvido seja efetivamente entregue aos estudantes.

Sendo assim, desenvolvemos uma lista de tarefas (check list) (Figura 2) em experiências próprias de planejamento e implementação de cursos do Centro de Desenvolvimento Docente da Faculdade de Medicina de Ribeirão Preto.

\section{CHECKLIST}

\section{de implementação de um curso online}

Listar todos os envolvidos como professores, tutores e equipe de apoio

$\square$ Realizar reunião para revisão de cronograma e alinhamento de aspectos e objetivos gerais do curso

Matricular todos os participantes no curso e distribuir login/senha para acesso ao ambiente virtual de aprendizagem

$\square$ Enviar mensagem de boas-vindas e orientações iniciais aos estudantes

$\square$ Criar um fórum de discussões (para interação coletiva) e outro canal privado (para comunicações entre professor e aluno)

Abrir uma sala de aula virtual

Acompanhar a conclusão das atividades e resolução de dúvidas

$\square$ Avaliar o curso pelos participantes/ docentes envolvidos

Atribuir devolutiva e nota para as avaliações formativas e somativas, respectivamente

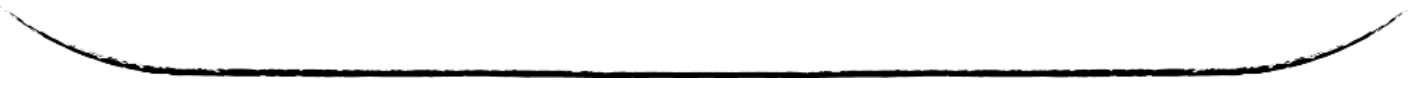

Figura 2: Sugestão de lista de tarefas para implementar curso oferecido remotamente em ambiente virtual de aprendizagem. 
Em tempo, as duas ilustrações desse texto foram feitas na plataforma Canva (https://www. canva.com/). Este site, mesmo na versão gratuita, permite ao usuário criar uma infinidade de designs de apresentações, gráficos, esquemas, infográficos, diversas comunicações ilustradas etc. Os modelos já existentes, fontes variadas e inúmeros elementos garantem a criação de recursos gráficos de aparência quase profissional.

É ainda neste momento que são realizados treinamentos necessários para que os professores e tutores possam aplicar o curso garantindo fidelidade ao que foi concebido até então e, ainda, certa homogeneidade no ensino, principalmente no que diz respeito à avaliação ${ }^{9}$. Caso haja tutores ou mais de um docente inclusos nas atividades avaliativas, é importante que o professor defina as diretrizes para a correção, já que os diferentes educadores podem ter concepções pedagógicas diversas sobre a avaliação criada pelo professor que desenvolveu o conteúdo ${ }^{6}$.

Apesar de uma aparente atuação passiva do professor que desenvolve o curso nesta etapa em comparação às anteriores, o papel ativo deste é intensificado, posto que na implementação, a análises de dúvidas e sugestões, adequação e aprimoramento dos materiais devem ser constantes para que o ensino possa ser efetivo. Ao utilizar as considerações dos alunos, alterações podem ser feitas ainda no decorrer das atividades de modo a garantir a eficiência do curso ${ }^{10}$.

Discussões entre docentes/tutores a respeito de dificuldades levantadas em questionários preenchidos pelos estudantes com opiniões a respeito do curso são boas fontes de informações para adequações e atualizações do material ou, ainda, identificação de situações complexas que surgem no cotidiano educacional.

Para tanto, comunicar-se é basilar, especialmente no contexto de ensino remoto. Uma comunicação clara e constante não somente garante a boa compreensão das atividades a serem desenvolvidas pelos estudantes, mas também permite ao professor alcançar a percepção dos estudantes sobre o curso, sendo fator preponderante para que haja o engajamento estudantil nas atividades propostas. É recomendável que o professor priorize as formas oficiais de comunicação, especialmente quando se referir a mudanças de datas e agendamento de atividades avaliativas, usando as mensagens enviadas pela plataforma de ensino ou ainda o e-mail institucional. Isso não quer dizer que o uso de redes sociais ou aplicativos de comunicação sejam desencorajados para comunicações rápidas, já que os estudantes costumam ter muita familiaridade com esses recursos.

No ensino remoto, independentemente da qualidade da tecnologia utilizada, o estudante invariavelmente não se sentirá próximo dos professores e demais colegas dadas a separação geográfica e temporal inerente a essa modalidade. Partindo do pressuposto da noção de "presença social", a intensidade da percepção do estudante de pertencer àquela experiência educacional será "diretamente proporcional ao grau de acesso, percebido por uma pessoa, à inteligência, às intenções e impressões sensórias de outra"11, ou seja, a comunicação permanente e compassiva é imprescindível para o compartilhamento e construção de saberes, sentimentos e atitudes.

Aliás, a "fórmula mágica" comumente utilizada na educação presencial - quanto maior a afetividade construída por meio da interação, maior será o engajamento do aluno - também pode ser aplicada ao ensino remoto. Isto porque, se nos orientarmos pela filosofia de Vygotsky no que diz respeito à afetividade, a "compreensão completa do pensamento humano só é possível quando se compreende sua base afetivo-voliti$v a^{\prime \prime 12}$. Desse modo, a comunicação encadeada nas conversas em chats e fóruns oferece substrato para que a afetividade possa ser observada nos ambientes virtuais de aprendizagem, dado que o contato físico é deslocado para a frequente interação dialógica ${ }^{13}$.

\section{Avaliar (Evaluate)}

A letra $E$ do acrônimo ADDIE, refere-se à avaliação (evaluation) do próprio projeto do design instrucional ${ }^{14}$. As finalidades são avaliar a qualidade das fontes de aprendizagem e quão bem elas atendem aos objetivos de ensino. Tratase, portanto, de um processo essencial e multidimensional, uma vez que inclui avaliar tanto o processo de design instrucional quanto o desempenho do estudante, como um reflexo direto da 
qualidade das oportunidades de aprendizagem ofertadas na unidade de ensino ou curso ${ }^{1}$.

Os métodos de avaliação do design empregados podem ser qualitativos ou quantitativos. Em geral, para avaliações quantitativas aplicamse escalas categóricas ordinais, como no caso da avaliação de satisfação dos estudantes com o conteúdo ou ambiente educacional virtual11,15. As avaliações qualitativas podem ser realizadas pelo agrupamento de temas emergentes obtidos de perguntas abertas, de acordo com a metodologia de análise de conteúdo ${ }^{16}$. Um exemplo de aplicação de avaliação qualitativa é uma pergunta aberta ao estudante sobre potenciais mudanças de comportamento diante dos conhecimentos adquiridos naquela unidade de ensino.

Conforme a representação esquemática ( $\mathrm{Fi}$ gura 2) da metodologia ADDIE, durante todo o desenvolvimento de uma unidade de ensino remoto, a avaliação servirá para retroalimentar cada uma das etapas com as informações sobre a adequação ou necessidades de melhorias. Nesse contexto, a avaliação do design instrucional tem uma característica mais formativa, ou seja, é conduzida antes da implementação definitiva, a fim de garantir que materiais e oportunidades estejam alinhados com os objetivos de aprendizagem e determinar se a qualidade do material didático satisfaz aos padrões estabelecidos na fase de desenvolvimento ${ }^{15}$.

$\mathrm{Na}$ etapa de avaliação de aprimoramento do design, pode-se conduzir os testes de aceitação do tipo Alfa e Beta, que auxiliam na construção da confiança e aumento da expectativa de satisfação e sucesso entre os estudantes ${ }^{17}$.

O teste do tipo Alfa é conduzido no âmbito mais interno do desenvolvimento do design instrucional. É a validação da versão preliminar e pode incluir parte da equipe envolvida, como docentes colaboradores, monitores e colegas especialistas no tópico, antes de efetivar a implementação da unidade de ensino. Alguns estudantes, que já foram aprovados naquele curso, podem ser intencionalmente envolvidos no teste Alfa, ainda com essa característica de teste de aceitação interna. As informações coletadas nesta fase são usadas para melhoria do conteúdo, em termos de correção e apresentação, e do ambiente educacional, em termos de acessibilidade, ausência de bugs, estética, entre outros.
O teste do tipo Beta nos é mais familiar porque muitas empresas de programas de computador e aplicativos para dispositivos móveis lançam versões Beta de seus produtos para coletar informações de um número restrito de usuários. No design instrucional, esse é o final da etapa de desenvolvimento, para um grupo de estudantes reais, externos à equipe de desenvolvimento do design instrucional. É, portanto, um teste de potenciais usuários do ambiente e do conteúdo em situação real. A versão Beta da unidade de ensino permite, por exemplo, testar o design em diferentes condições de acesso ou dispositivos, recolher informações e corrigir problemas antes de iniciar oficialmente a disciplina, por exemplo. Após o teste Beta, a unidade de ensino ou curso está pronta para seu primeiro oferecimento.

Se por qualquer motivo, qualquer uma das etapas de teste Alfa e Beta tiverem que ser suprimidas, você pode fazer uma reflexão sobre sua unidade de ensino ou curso, usando as perguntas frequentemente utilizadas nessas duas avaliações que estão no Quadro $3^{8}$. Esses tópicos de avaliação também servem como sugestões para quem vai conduzir os testes Alfa e Beta.

Quando uma turma ou oferecimento do curso é concluído, deve-se realizar uma avaliação para detectar o quanto a unidade foi eficaz em propiciar o aprendizado dos objetivos elencados na fase de análise. Nesse contexto, a avaliação tem um caráter mais somativo ou classificatório e pode contemplar os quatro níveis do modelo de Kirkpatrick ${ }^{9,18}$. Os quatro níveis de avaliação são: (1) a reação do estudante sobre a experiência de ensino, incluindo sua satisfação e aprovação; (2) o aprendizado em termos de aquisição de conhecimento, habilidade ou competência; (3) as mudanças de comportamento e transferência do que aprendeu para prática profissional; e (4) os resultados ou o impacto sobre os cuidados prestados pelo estudante e futuro profissional. Assim como acontece no ensino presencial, em geral, as avaliações do design instrucional em ensino remoto se concentram nos primeiros dois níveis, especificamente, a reação do estudante diante da experiência de aprendizagem, através de autorrelatos fornecidos de forma anônima, e o conhecimento adquirido por meio de avaliação somativa da unidade de ensino ${ }^{5,19}$. 
Quadro 2. Recomendações de software gratuito, hardware mínimo, e formatos digitais abertos (open format) para produção de material didático. Em negrito estão os formatos mais recomendados.

\begin{tabular}{|c|c|c|c|}
\hline $\begin{array}{l}\text { Tipo de } \\
\text { conteúdo }\end{array}$ & Software (gratuito) & Hardware & Formato digital aberto \\
\hline $\begin{array}{l}\text { Textos, slides } \\
\text { ou planilhas de } \\
\text { dados }\end{array}$ & 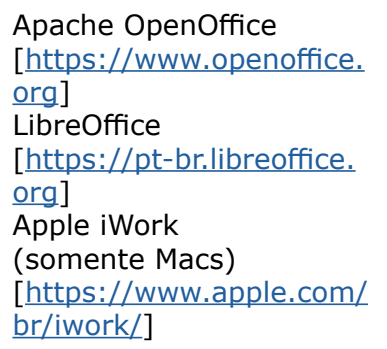 & Apenas um computador & $\begin{array}{l}\text { PDF (mais utilizado para tex- } \\
\text { to), CSV (mais utilizado para } \\
\text { planilhas), TXT (texto sim- } \\
\text { ples), EPUB (para e-books), } \\
\text { HTML (conteúdo web, intera- } \\
\text { tivo), LaTeX (mais usado para } \\
\text { teses e dissertações), Office } \\
\text { Open XML, OpenDocument. }\end{array}$ \\
\hline Áudios & $\begin{array}{l}\text { Audacity } \\
\text { [https://www.audacityte- } \\
\text { am.org] }\end{array}$ & $\begin{array}{l}\text { Gravador de voz }+ \text { microfone de } \\
\text { lapela } \\
\text { OU } \\
\text { Telefone celular com fone de } \\
\text { ouvido e microfone integrado } \\
\text { OU } \\
\text { Microfone de lapela ou profissio- } \\
\text { nal conectado diretamente a seu } \\
\text { computador }\end{array}$ & $\begin{array}{l}\text { MP3 (mais utilizado), OGG } \\
\text { (menos comum), FLAC (sem } \\
\text { perda de qualidade), WAV } \\
\text { (formato antigo, arquivos } \\
\text { grandes). }\end{array}$ \\
\hline Imagens & $\begin{array}{l}\text { GIMP } \\
\text { [https://www.gimp.org] } \\
\text { Canva } \\
\text { [https://www.canva.com/ } \\
\text { pt_br/] }\end{array}$ & $\begin{array}{l}\text { Computador com boa memória } \\
\text { RAM (pelo menos } 8 \mathrm{~GB} \text { ) e boa } \\
\text { capacidade de processamento } \\
\text { Câmera fotográfica (mínimo } 8 \\
\text { megapixels, equivalente a reso- } \\
\text { lução 4k/Ultra HD) } \\
\text { OU } \\
\text { A câmera do seu telefone celular }\end{array}$ & $\begin{array}{l}\text { JPEG e JPEG } 2000 \text { (mais } \\
\text { utilizados, com perda de } \\
\text { qualidade), PNG (mais comum } \\
\text { em Macs), GIF (especialmen- } \\
\text { te os animados), TIFF (sem } \\
\text { perda de qualidade, arquivos } \\
\text { grandes). }\end{array}$ \\
\hline Vídeos & $\begin{array}{l}\text { Shotcut } \\
\text { [https://shotcut.org] } \\
\text { OpenShot } \\
\text { [https://www.openshot. } \\
\text { org/pt/] }\end{array}$ & $\begin{array}{l}\text { Computador com boa memória } \\
\text { RAM (pelo menos } 8 \mathrm{~GB} \text {, ide- } \\
\text { almente } 16 \mathrm{~GB} \text { ou mais), boa } \\
\text { capacidade de processamento } \\
\text { (mínimo quadcore, } 3 \mathrm{GHz} \text { ), e dri- } \\
\text { ve SSD (mais veloz), além de HD } \\
\text { externo para armazenamento } \\
\text { Câmera fotográfica (mínimo } 8 \\
\text { megapixels, equivalente a reso- } \\
\text { lução 4k/Ultra HD) } \\
\text { OU } \\
\text { A câmera do seu telefone celular } \\
\text { OU } \\
\text { Uma webcam com pelo menos } \\
\text { resolução FullHD (1920 x 1080) } \\
\text { OU } \\
\text { Uma filmadora profissional de- } \\
\text { dicada }\end{array}$ & $\begin{array}{l}\text { MP4 (mais comum, mais } \\
\text { compatível, embora não seja } \\
\text { open format), MOV (mais co- } \\
\text { mum em Macs), MKV (menos } \\
\text { comum, menos compatível), } \\
\text { MPEG (formato antigo, com } \\
\text { perda de qualidade), AVI } \\
\text { (somente computadores com } \\
\text { Windows, não é open format). }\end{array}$ \\
\hline
\end{tabular}




\section{CONSIDERAÇÕES FINAIS}

É importante que o professor, ao iniciar o planejamento de um curso ou uma disciplina remota, reconheça que o objetivo primário é o engajamento do estudante e, consequentemente, a aprendizagem do que for estabelecido nos objetivos educacionais propostos. Isto pode ser mais facilmente atingido ao se definir objetivos claros, adequados e passíveis de serem alcançados, e ao se criar um ambiente educacional que atenda às diferentes necessidades do indivíduo, seguro e inclusivo, que considere questões de acessibilidade, tornando a experiência do estudante significativa, agradável e recompensadora. Por último, o professor deve lembrar-se de ensinar ao estudante não somente o "seu" conteúdo, mas também de ensinar as habilidades que o estudante precisa desenvolver para um mundo cada vez mais digital.

\section{REFERÊNCIAS}

1. Khalil MK, Elkhider IA. Applying learning theories and instructional design models for effective instruction. Adv Physiol Educ. 2016;40(2):147-56.

2. Santos LMA, Tarouco LMR. A Importância do estudo da teoria da carga cognitiva em uma educação tecnológica. Renote. 2007;5(1).

3. Gustafson $\mathrm{KL}$, Branch RM. What is Instructional Design? In R. A. Reiser \& J. A. Dempsey (Eds.). Trends and issues in instructional design and technology. 2002:16-25.

4. Dick W, Carey L, Carey JO. The systematic design of instruction. Boston: Pearson/Allyn and Bacon; 2005.

5. Patel SR, Margolies PJ, Covell NH, Lipscomb C, Dixon LB. Using Instructional Design, Analyze, Design, Develop, Implement, and Evaluate, to Develop e-Learning Modules to Disseminate Supported Employment for Community Behavioral Health Treatment Programs in New York State. Front Public Health. 2018;6:113.
6. Gava TBS, Nobre IAM, Sondermann DVC. O modelo ADDIE na construção colaborativa de disciplinas a distância. Informática na educação: teoria \& prática. 2014;17(1).

7. Vogt MSL, Alves ED. Revisão teórica sobre a educação de adultos para uma aproximação com a andragogia. Educação (UFSM); educação v 30, n 2, jul/dez 2005. 2005.

8. Tobase L, Peres HHC, Almeida DM, Tomazini EAS, Ramos MB, Polastri TF. Instructional design in the development of an online course on Basic Life Support. Rev Esc Enferm USP. 2018; 51 :e03288.

9. Gavarkovs AG, Blunt W, Petrella RJ. A protocol for designing online training to support the implementation of community-based interventions. Eval Program Plann. 2019;72:77-87.

10. Peterson C. Bringing ADDIE to Life: Instructional Design at Its Best. Journal of Educational Multimedia and Hypermedia. 2003;12(3):227-41.

11. Paiva DCd, Jasbick DL. TORI, Romero. Educação sem distância: as tecnologias interativas na redução de distâncias em ensino e aprendizagem. Revista Inter Ação. 2017;42(1):233-7.

12. La Taille YJJMRd, Oliveira MKd, Pinto HDdS. Piaget, Vygotsky, Wallon: teorias psicogenéticas em discussão. São Paulo: Summus; 2000.

13. Chantal Duarte Silva P, Shitsuka R, Gomes Paschoal PA. Afetividade nas interações em AVA: um estudo sobre a interação na educação a distância. Revista Brasileira de Aprendizagem Aberta e a Distância. 2015;14.

14. Bates AW. Educar na era digital: design, ensino e aprendizagem. São Paulo 2017. 48 p.

15. Awaisu A, Khalifa S, Mottram D, Ahmed A, Stuart M. Instructional design and assessment of an elective course on the use of drugs in sport. Curr Pharm Teach Learn. $2018 ; 10(8): 1124-31$.

16. Bardin L. Análise de conteúdo. São Paulo 2011. 229 p.

17. Lee-Jayaram JJ, Berg BW, Sy A, Hara KM. Emergent Themes for Instructional Design: Alpha and Beta Testing During a Faculty Development Course. Simul Healthc. $2019 ; 14(1): 43-50$.

18. Battles JB. Improving patient safety by instructional systems design. Qual Saf Health Care. 2006;15 Suppl 1:i25-9.

19. Bollela VR, Castro M. Avaliação de programas educacionais nas profissões da saúde: conceitos básicos. Medicina (Ribeirão Preto). 2014;47(3):333-42. 


\section{Contribuições específicas:}

Todos os autores contribuíram na idealização, redação e revisão do manuscrito.

\section{Financiamento:}

Não houve.

Editor:

Prof. Dr. Marcelo Riberto

Recebido: 30/04/2021

Aprovado: $13 / 07 / 2021$

(c) (i) Este é um artigo publicado em acesso aberto (Open Access) sob a licença Creative

sem restriç̃os, desc, que perabalho, 